\title{
Documentário Autobiográfico e Feminismo: 0 quarteto de filmes de Miriam Weinstein
}

\author{
Autobiographical Documentary and Feminism: \\ Miriam Weinstein's quartet of films
}

\section{Coraci Ruiz}

É doutora em Multimeios pelo Instituto de Artes da Unicamp. Este artigo está vinculado à tese de doutorado "Documentário autobiográfico de mulheres: tecnologias, gestos e estéticas da resistência", defendida em setembro de 2020.

Email: coraci@laboratoriocisco.org

\section{RESUMO}

O documentário autobiográfico herdeiro da tradição do cinema direto foi desenvolvido pelos cineastas de Cambridge, agrupados no centro de ensino, pesquisa e produção cinematográfica do MIT, o MIT Film Section. Membro do grupo, Miriam Weinstein realizou, na década de 1970, quatro documentários de curta-metragem: My father the Doctor (1972); Living With Peter (1973); We Get Married Twice (1973) e Cal Me Mama (1976). Neste artigo discutiremos como as contribuições estético-políticas de sua obra constituem parte do legado de toda uma geração de cineastas mulheres feministas.

PALAVRAS-CHAVE: documentário autobiográfico; feminismo; teoria feminista de cinema.

\section{ABSTRACT}

The autobiographical documentary inheriting from the direct cinema tradition was developed by Cambridge filmmakers gathered around MIT's center for film teaching, research and production, the MIT Film Section. Part of this group, Miriam Weinstein made four short documentaries in the 1970s: My father the Doctor (1972); Living With Peter (1973); We Get Married Twice (1973) and Cal Me Mama (1976). In this article we will discuss how the aesthetic-political contributions of her work constitute part of the legacy of an entire generation of feminist women filmmakers.

KEYWORDS: autobiographical documentary; feminism; feminist theory of cinema.

Submetido em 29 de Agosto de 2020

Aceito em 06 de Dezembro de 2020

Dossiê Feminismos vitais - https://revistaecopos.eco.ufri.br/

ISSN 2175-8689 - v. 24, n. 1, 2021

DOI: 10.29146/ecopos.v24i1.27603 


\section{Introdução ${ }^{1}$}

Este artigo analisa como os filmes de Weinstein contribuem para o diálogo entre o feminismo e o documentário autobiográfico. 0 documentário autobiográfico herdeiro da tradição do cinema direto foi desenvolvido pelos cineastas de Cambridge ${ }^{2}$, que se reuniam no centro de ensino, pesquisa e produção cinematográfica do MIT, o MIT Film Section, fundado em 1968 por Ed Pincus e Richard Leacock, onde numerosos cineastas realizaram filmes a partir de pesquisas e experimentações com a presença da câmera em seus universos pessoais. Como participante do grupo, Miriam Weinstein realizou, na década de 1970, quatro documentários autobiográficos de curta-metragem: My father the Doctor (1972); Living With Peter (1973); We Get Married Twice (1973) e Cal Me Mama (1976) $)^{3}$.

Weinstein não foi aluna do MIT Film Section, "porém mantinha contato com representantes da produção de Cambridge, reunindo-se com Ed Pincus e outros cineastas", como conta Gabriel Tonelo (2017, p. 148). Em um depoimento citado por Scott MacDonald, Weinstein comenta o seguinte: "em 1968, que foi uma época de tremenda convulsão social, os jovens dos meios de comunicação reuniam-se na casa/escritório de Ed Pincus. Havia muita discussão sobre como cobriríamos os eventos que estavam acontecendo" (MacDonald, 2013, p. 131).

MacDonald contextualiza o surgimento dos filmes autobiográficos a partir da agitação social que aconteceu nos EUA no final dos anos 1960 e a consequente revisão de valores que diversas instituições - e a sociedade de maneira geral - foram levadas a fazer:

Sob a pressão de estudantes e professores as faculdades e universidades começaram a repensar sua exclusividade econômica e étnica. E uma nova onda do feminismo estava questionando a natureza das relações entre homens e mulheres, a instituição do

\footnotetext{
1 O presente trabalho foi realizado com apoio da Coordenação de Aperfeiçoamento de Pessoal de Nível Superior - Brasil CAPES - Código de Financiamento 88882.461722/2019-01

2 Região de Boston, EUA, com alta concentração de centros universitários e de pesquisa, como, por exemplo, a Universidade de Harvard, o MIT (Instituto de Tecnologia de Massachusetts), a Boston University, o Emerson College e a Berklee College of Music.

3 Os filmes de Weinstein estão disponíveis no website da diretora: http://www.miriamweinstein.com. Acesso em 13 ago. 2020.
}

Dossiê Feminismos vitais - https://revistaecopos.eco.ufri.br/

ISSN 2175-8689-v. 24, n. 1, 2021

DOI: 10.29146/ecopos.v24i1.27603 
casamento e um dos pressupostos centrais da família americana nuclear, a crença na privacidade. (...) Dentro deste clima social volátil, não é de surpreender que, para uma nova geração, fazer filmes torne-se um meio de investigar tradições problemáticas e promover mudanças culturais. (...) E em Cambridge e em outros locais, os realizadores de documentários começaram a levar as câmeras de $16 \mathrm{~mm}$ e de vídeo para o interior das relações familiares e pessoais, a fim de ver o que poderia ser aprendido sobre as maneiras pelas quais a experiência diária refletia ideias problemáticas e padrões sociais. (MacDonald, 2013, p. 127-128, tradução nossa).

Com efeito, a produção de documentários autobiográficos surge como uma resposta de cineastas para um momento de crise e transformação dentro de sólidas instituições sociais. MacDonald aponta que, naquele grupo, houve duas maneiras principais de conduzir as investigações autobiográficas: uma delas era filmar o confronto direto com os próprios familiares, de modo a entender o funcionamento das famílias e as respectivas posições dentro delas; a outra era voltar-se para as gerações anteriores mediante a utilização de material de arquivo, para rever como as famílias tradicionais funcionavam e como os membros mais velhos entendiam as mudanças em curso. Em seu quarteto de filmes, Weinstein navegou pelas duas vertentes, ao mesmo tempo em que lançou mão de diferentes estratégias narrativas, como entrevistas, voz over, monólogos para a câmera, uso de som direto e trilha sonora, demonstrando a capacidade inventiva e a liberdade de experimentação estética com que formulou sua obra.

A emergência da voz de Weinstein, uma das poucas mulheres diretoras em um quadro de cineastas majoritariamente masculino, revela um momento histórico no qual as mulheres passam a se autoafirmar como sujeitos do discurso. Nesse mesmo período, cineastas e artistas estadunidenses provenientes de outros contextos e formações - e a partir de diferentes matrizes estéticas - também experimentavam a autoinscrição a partir da câmera de cinema e de vídeo. Entre elas, podemos citar Ilene Segalove4, que lançou, em 1974, The mom's tapes, uma série de esquetes curtas em vídeo, nas quais, a partir do humor, desafia as regras de comportamento impostas pela mãe como forma de conquistar autonomia; e Barbara Hammer5, que em filmes experimentais como Marie and me (1970) e Superdyke meets madame X (1976), filma a si mesma e a sua amante em cenas cotidianas de nudez e carícias, colocando a

\footnotetext{
$4 \quad$ Artista e videomaker formada em Belas Artes pela Universidade da Califórnia.

5 Cineasta e ativista feminista formada em psicologia pela Universidade da Califórnia e em cinema pela Universidade Estadual de São Francisco.
}

Dossiê Feminismos vitais - https://revistaecopos.eco.ufri.br/

ISSN 2175-8689-v. 24, n. 1, 2021

DOI: 10.29146/ecopos.v24i1.27603 
sexualidade e o companheirismo lésbicos em evidência como fontes geradoras de força transgressora.

Esses filmes, assim como os de Weinstein e muitos outros realizados no período, investem na premissa feminista, tantas vezes repetida, de que o pessoal é político, e elegem como estratégia estético-política a escrita autobiográfica, de modo que as diretoras exploram o seu cotidiano e sua intimidade para mostrar e questionar os papéis sociais reservados às mulheres. Assim, a obra de Weinstein, uma das primeiras cineastas mulheres a filmar a própria privacidade (MacDonald, 2013), faz parte de um momento importante para o encontro entre o feminismo e o documentário, que, na época, começava a se efetivar.

\section{0s filmes de Miriam Weinstein}

Além de fazer amplo uso de material de arquivo - com muitas fotos e muitos filmes caseiros de família -, My father the doctor (1972), o primeiro filme de Weinstein, se estrutura por meio de algumas entrevistas que a diretora realiza com seu pai. Em um primeiro momento, ele fala sobre sua trajetória familiar, de estudos e profissional, até se tornar médico. Já em um segundo momento, as entrevistas exploram sua visão sobre a filha e as escolhas profissionais dela. A diretora não aparece na tela, mas ouvimos sua voz, que faz perguntas por detrás da câmera. As opiniões expressas pelo pai de Miriam demonstram que ele acredita que existem sim habilidades e papéis distintos para homens e mulheres ("poucas mulheres são boas médicas, pois é uma atividade muito intensa"6), mas não compactua com a ideia de que às mulheres deve ser reservado somente o universo doméstico. Ao afirmar que considera a filha inteligentíssima ("um cérebro"), diz que havia imaginado ou esperado que ela se dedicasse a alguma área da ciência. Para ele, a carreira de cineasta é um desperdício.

Durante a entrevista, é a diretora quem pergunta sobre as expectativas do pai sobre ela: "O que você pensa sobre eu ser cineasta?"; "O que você esperava de mim?"; "Você tem mais alguma coisa a dizer sobre as suas expectativas sobre mim?". O pai mostra-se conformado com as escolhas da filha, e em todas as respostas deixa claro que as suas expectativas ou frustrações, apesar de existirem, não são significativas: "Se você está feliz com esse trabalho... esse é o seu

6 A tradução dos diálogos dos filmes de Miriam Weinstein são livres, feita pela própria autora deste artigo.

Dossiê Feminismos vitais - https://revistaecopos.eco.ufri.br/

ISSN 2175-8689-v. 24, n. 1, 2021

DOI: 10.29146/ecopos.v24i1.27603 
trabalho". Quando o pai afirma que a medicina não é uma profissão apropriada para mulheres, Miriam questiona: "Se eu fosse um menino você iria querer que eu fosse um médico?". Ao que ele responde: "Eu gostaria, mas não teria pressionado para isto". Com tais perguntas, Weinstein chama a atenção para a visão sexista do pai e revela valores entranhados na família, que não só hierarquizam homens e mulheres como definem o tipo de trabalho considerado relevante ou meritório.

Em Living with Peter (1973), seu segundo filme, Weinstein desloca o foco do pai para o papel do casamento em sua vida. A questão central agora é a ansiedade experimentada pela diretora na situação de viver com o namorado Peter sem ter formalizado a relação. Apesar de ser algo, como ela mostra no filme, já comum na época - não era malvisto pela família ou pelos amigos -, a situação a incomodava. 0 curta-metragem é composto, principalmente, por entrevistas com o companheiro, com a mãe, com alguns amigos, e por monólogos que a diretora faz diretamente para a câmera, em que disserta sobre a sua angústia em relação à formalização do casamento.

$\mathrm{Na}$ abertura, vemos Peter, então namorado de Weinstein, sem camisa, muito magro e careca brincando de fazer poses másculas - rindo, ele cerra o punho e dobra o braço para salientar os músculos e se vira de um lado para o outro. A conversa que se segue, um tanto truncada, apresenta a relação do casal a partir de sentimentos conflitantes. Ela pede que ele se apresente; Peter, depois de dizer que vive com Miriam, acrescenta: "O que às vezes gosto, às vezes não". E ela replica: "Achei que você gostasse o tempo todo". Ao que ele responde: "Não... você também não gosta o tempo todo".

Na entrevista, Peter, que faz a barba enquanto responde, mostra-se incomodado, o que transparece em sua relativa resistência às perguntas e em alguma rispidez nas respostas. Em seguida, em um monólogo que se dá no quarto - e durante o qual dobra algumas roupas que estão jogadas na cama -, Weinstein conta que, por ela e Peter não serem casados, um problema burocrático havia se criado com a companhia seguradora, e reconhece que tinha o desejo de usar o imbróglio como desculpa para se casar. Nessas cenas, a diretora revela uma visão nada romantizada do casamento, apesar da vontade de concretizá-lo.

O filme segue com entrevistas com amigos e familiares, que colocam opiniões favoráveis e contrárias ao casamento formal. Quando entrevistada, a mãe de Miriam afirma que não vê 
problema na situação, mas acha que no momento de "passar ao próximo passo", referindo-se a ter filhos, seria importante casar: "uma mulher naturalmente quer ter filhos e naturalmente quer casar". A fala é sucedida por uma entrevista com a irmã de Peter, uma jovem mulher que defende exatamente o oposto: não suporta crianças, não quer ter filhos e não quer formalizar o casamento. Um casal, que optou entusiasticamente por se casar antes de viver junto, também é entrevistado, de maneira que distintas opiniões e experiências em relação ao casamento são postas em discussão. Não há um recorte geracional a determinar as diferenças entre as visões dos personagens: a sequência mostra que a instituição do casamento estava sendo questionada e debatida, o que era algo razoavelmente recente naquele momento.

Peter, o companheiro de Miriam, aparece em diversos momentos. Durante a primeira entrevista, ele afirma categoricamente que não deseja se casar, pois “[...] dá muito trabalho, exige muito esforço e toma muito tempo". Perto do final, em outra entrevista - Peter está deitado confortavelmente no sofá -, ficamos sabendo que ele havia finalmente se rendido e presenteado a companheira com um anel de noivado. $\mathrm{Na}$ última sequencia ela retoma o monólogo, explicando que deseja o casamento mais do que Peter, e que falar sobre o tema é o motivo pelo qual ela faz o filme. Encerra dizendo que está feliz com o anel e a perspectiva de se casar.

No curta-metragem seguinte, We get married twice (1973), a diretora relata o esperado casamento e o fato de se terem realizado duas cerimônias: a primeira, celebrada na tradição judaica, em Nova Iorque, pelo mesmo rabino que havia casado seus pais; a segunda, não religiosa e dedicada a amigos próximos, na casa de Miriam e Peter. A primeira parte do filme é conduzida pela voz over: fotografias e imagens em movimento das duas cerimônias aparecem sob as vozes de Peter e Weinstein dando explicações sobre o casamento duplo. Os noivos não tiveram a permissão do rabino para filmar a cerimônia na sinagoga, de modo que sobre a tela preta ouvimos apenas o seu registro sonoro. Já a festa do segundo casamento havia sido devidamente filmada, e nela foram realizadas diversas entrevistas com familiares e amigos, identificados por suas relações com a diretora - "minha irmã", "minha amiga", etc. -, nas quais se expressam opiniões sobre o casamento. No final, o casal está reunido em casa com um grupo de amigos, ainda com as roupas do casamento, e avalia positivamente as duas cerimônias.

Dossiê Feminismos vitais - https://revistaecopos.eco.ufri.br/

ISSN 2175-8689 - v. 24, n. 1, 2021

DOI: 10.29146/ecopos.v24i1.27603 
Por fim, em Call me mama (1976) a cineasta aborda as dores e as delícias da maternidade. Esse é o único filme em que ela utiliza trilha sonora. Depois de mostrar algumas fotografias com o filho, a diretora se apresenta diretamente para a câmera:

Meu nome é Miriam Weinstein, eu tenho trinta anos e venho trabalhando como cineasta nos últimos dez anos. Há três anos, eu decidi ter um bebê. Eu sempre quis ter um filho, e eu pensei que o meu casamento e a carreira estavam sólidos o suficiente e que não haveria muitas adaptações (informação verbal).

O depoimento segue, agora em off, por todo o filme: a narração aborda os medos, as preocupações e a exaustão da maternidade, as dificuldades em fazer o filme e a displicência do marido, reiterada pela sua total ausência nas imagens. Sobre ele, a diretora afirma que "não é o tipo de pessoa que cuida de um bebê". Weinstein passeia com o filho no parque e visita uma amiga de infância que também tem uma criança pequena. No final, já em casa, enquanto lê um livro para o filho, comenta na narração que as crianças precisam muito de proximidade e de rotina, e que ela, como mãe, vive no mesmo mundo, um lugar que não faz nada pelo seu intelecto ou para as suas ambições, mas que "pode fazê-la feliz se você simplesmente relaxar e aproveitar". Por fim, acrescenta que a profissão é de fato colocada de lado, já que gasta toda a energia mental com a criança. No entanto, reconhece que já não se sente tão exausta e que teria outro filho.

Weinstein construiu as narrativas de seus documentários primeiro do ponto de vista da filha, depois da mulher/esposa e finalmente da mãe, ou seja, os papéis sociais destinados a atravessar a vida de uma mulher. Mas não só: a profissão de cineasta, além de implicitamente presente no próprio ato de dirigir os filmes, é tematizada em todos eles, evidenciando a relevância da carreira profissional em sua vida e as dificuldades em conciliá-la com as demandas e as expectativas domésticas ${ }^{7}$. Assim, as interações e os tensionamentos entre o espaço público e o privado aparecem em seus filmes como elementos constitutivos da experiência da mulher - algo que era compartilhado e expresso por muitas outras cineastas, e que ocupava um lugar importante no pensamento e na ação feministas da época.

$7 \quad$ Nos anos seguintes ela deixou de ser cineasta e tornou-se escritora, publicando quatro livros (The Surprising Power of Family Meals: How Eating Together Makes Us Smarter, Stronger, Healthier and Happier; Yiddish: A Nation of Words; Prophets and Dreamers: A Selection of Great Yiddish Literature; e All Set For Black, Thanks: A New Look at Mourning), além de manter um blog sobre avós: <http://www.miriamweinstein.com/?page id=570>. Acesso em 20 ago. 2020.

Dossiê Feminismos vitais - https://revistaecopos.eco.ufrj.br/

ISSN 2175-8689 - v. 24, n. 1, 2021

DOI: 10.29146/ecopos.v24i1.27603 


\section{Feminismo e "diferença sexual"}

O desenvolvimento autobiográfico de Weinstein passa, fundamentalmente, pelas expectativas e frustrações geradas pela instituição familiar em seus diversos pontos: sua vida profissional em relação à visão do pai, sua expectativa quanto ao casamento e, por fim, suas crises e realizações como mãe. O lugar da mulher é tanto questionado como construído em oposição às figuras masculinas do pai e do marido, podendo-se identificar em suas narrativas o pensamento feminista baseado na diferença sexual, o que revela uma cineasta em plena sintonia com o seu tempo: os filmes de Weinstein refletem as preocupações e contribuem para as discussões de uma grande vertente do feminismo de sua época, de seu país e de sua classe social.

Apesar das críticas que tal posicionamento recebeu nos anos seguintes, ele foi fundamental no desenvolvimento da produção e da crítica feministas, e não apenas no campo cinematográfico. Teresa de Lauretis sugere que nos anos 1960 e 1970 o conceito de gênero como diferença sexual “encontrava-se no centro da crítica da representação" (Lauretis, 1994, p. 206), e explica: “com sua ênfase no sexual, a 'diferença sexual' é antes de mais nada a diferença entre a mulher e o homem, o feminino e o masculino" (ibidem, p. 207). Décadas à frente daquele período, ao propor que o gênero fosse visto como fruto de um complexo processo de produção que se dá por meio de diferentes tecnologias ${ }^{8}$, ela aponta para as limitações que o conceito de diferença sexual impõe, sendo a primeira delas confinar "o pensamento crítico feminista ao arcabouço conceitual de uma oposição universal do sexo (...), o que torna muito difícil, se não impossível, articular as diferenças entre mulheres" (ibidem, p. 207). Desse modo, a autora questiona o feminismo que não incorpora diferenças de raça e classe, acabando por reduzir-se a questões relacionadas à vida de mulheres brancas de classe média e alta.

\footnotetext{
$8 \quad$ No texto "A tecnologia do gênero" (traduzido para o português e publicado no Brasil no livro "Tendências e impasses: o feminismo como crítica cultural", organizado por Heloísa Buarque de Holanda em 1994), a autora defende que o gênero é uma construção social produzida por diferentes tecnologias presentes na sociedade: “... pode-se começar a pensar o gênero a partir de uma visão foucaultiana, que vê a sexualidade como uma 'tecnologia sexual'; desta forma, propor-se-ia que também o gênero, como representação e autorrepresentação, é produto de diferentes tecnologias sociais, como o cinema, por exemplo, e de discursos, epistemologias e práticas críticas institucionalizadas, bem como das práticas da vida cotidiana" (Lauretis, 1994, p. 208).
} 
A incorporação das questões de classe é também um ponto importante nas análises de Elizabeth Ann Kaplan (1988), que defende que a perspectiva ideológica de um filme é um ponto fundamental para a sua análise, dividindo os filmes feministas da época em dois grandes campos ideológicos dentro do feminismo: um deles "exibia uma clara política ativistaesquerdizante", enquanto o outro "revelava uma postura mais liberal burguesa" (Kaplan, 1988, p. 182). Segundo a autora, os filmes esquerdistas demonstravam uma preocupação com a "conscientização quanto à exploração da mulher trabalhadora em um sistema capitalista", enquanto os filmes liberais burgueses, apesar de revelarem como os papéis sociais privilegiam os homens, não analisavam as causas das hierarquias nem as relacionavam às questões de raça e de classe. Ao mesmo tempo, os filmes feministas liberais burgueses "instavam a mulher a tentar libertar-se de papéis sexuais que limitassem suas oportunidades para uma vida individual rica, satisfatória e desafiadora", ou seja, não tinham uma perspectiva coletiva e estrutural das mudanças políticas reivindicadas.

Desde aquela época até os dias de hoje, o feminismo vem complexificando suas análises e práticas. As críticas elaboradas por Lauretis e Kaplan fazem parte da transformação gerada sobretudo a partir das proposições de importantes feministas negras. A noção de interseccionalidade, que sintetiza uma visão segundo a qual diversas formas de opressão interagem e não devem ser analisadas separadamente, é proposta por Kimberlé Crenshaw, em 1989, embora a discussão já estivesse sendo feita por diversas autoras, como Ângela Davis, bell hooks, Lélia Gonzalez e Patrícia Hill Collins, que publicaram importantes textos na década de 1980.

Com efeito, as narrativas de Weinstein, que acompanham quase uma década de sua vida, demonstram preocupações e questionamentos próprios de uma jovem mulher norteamericana, branca, heterossexual e de classe média nos anos 1970: uma mulher que decide seguir uma profissão que, apesar de não ser a esperada pelo pai, lhe dá satisfação, e na qual é bem sucedida; que deseja se casar com um homem e de fato se casa, inclusive em duas cerimônias, de modo a agradar tanto aos amigos progressistas quanto à família conservadora; e que encontra a felicidade na maternidade, apesar da falta de participação do marido, das crises intelectuais e do cansaço. Sua trajetória pessoal expõe algumas das opressões de gênero e, ao mesmo tempo, afirma a possibilidade de, individualmente, ultrapassá-las ou aceitá-las. 
Contudo, não aponta para uma transformação social estrutural. Seria possível, portanto, pensar o quadro de expectativas e de frustrações desenhado por Weinstein em seus filmes a partir das análises de Kaplan sobre o "pensamento feminista liberal burguês".

Mas é importante ressaltar que Weinstein faz parte de uma geração pioneira de mulheres a empunhar a câmera e apontá-la para os homens de sua família. 0 amadurecimento do pensamento feminista e da produção e crítica cinematográficas só se deu porque mulheres como ela desbravaram caminhos e expandiram fronteiras. Weinstein lidou com os dilemas da construção de uma voz própriaem um contexto dominado pelo masculino, no qual os estudos feministas ainda não faziam parte das rotinas acadêmicas. Assim, se encontramos limites nesse gesto inaugural ao assumirmos certo distanciamento histórico, é essencial contextualizar a obra de Miriam Weinstein para compreender sua importância para o desenvolvimento do documentário feminista.

\section{Feminismo e documentário}

Diane Waldman e Janet Walker, que em 1999 organizaram o livro Feminism and Documentary, afirmam que os campos do feminismo e do documentário, apesar de seus interesses em comum, por muito tempo estiveram apartados:

Dada a longa associação do documentário aos movimentos sociais progressistas, a oposição tanto dos documentaristas como das feministas ao cinema dominante e o interesse de ambos em desenvolver e apoiar alternativas ao mesmo, poder-se-ia supor que estas áreas de estudo teriam muito em comum. Mas, na sua maioria, os dois não tiveram muito a dizer um ao outro (Waldman; Walker, 1999, p. 3-4, tradução nossa).

O livro tem como objetivo fomentar o diálogo entre o feminismo e o documentário ao reunir um conjunto de artigos que abordam a intersecção entre os dois campos, mostrando que, embora tardiamente, a aproximação aconteceu e passou a suscitar um fértil debate.

Nos primeiros anos de desenvolvimento da teoria feminista de cinema, ganhou força o embate entre as que acreditavam no potencial político de documentários feministas ancorados nas técnicas observacionais - que faziam parte do repertório do documentário clássico ou 
mainstream - e aquelas que as recusavam, reivindicando que o cinema feminista só seria possível se rejeitasse e desconstruísse os códigos do cinema dominante9.

Segundo Waldman e Walker (1999), as ativistas da segunda onda feminista viram com entusiasmo a possibilidade, recém-conquistada pelo desenvolvimento de tecnologias de filmagem mais leves e baratas, de usar o documentário como ferramenta para sua militância. Naquele primeiro momento, o efeito realista do cinema direto foi celebrado, por exemplo, pela teórica Dora Kaplan ${ }^{10}$. Mas justamente este pressuposto - a captura de um real puro - foi o que levou outras feministas a abandonarem as técnicas documentais.

As autoras ressaltam que o artigo Women's Cinema as Counter-Cinema, de Claire Johnston, teve um papel fundamental na construção da "posição contra o cinema direto ou o documentário de cinema verité como uma estratégia eficaz" (Waldman; Walker, 1999, p. 8, tradução nossa) para os propósitos do cinema feminista. A argumentação, apropriada e aprofundada nos anos seguintes por outras teóricas feministas, era baseada na ideia de que a forma como os filmes eram construídos era tão importante quanto o seu conteúdo:

0 perigo de desenvolver um cinema de não-intervenção é que promove uma subjetividade passiva à custa da análise. Qualquer estratégia revolucionária deve desafiar a representação da realidade. Não basta discutir a opressão das mulheres no texto do filme. A linguagem do cinema e a representação da realidade também devem ser interrogadas, para que se faça uma ruptura entre a ideologia e os textos (Johnston, 1973, p. 29, tradução nossa).

O antirrealismo tornou-se, assim, uma vertente importante do pensamento e da produção de documentários feministas. Mas, também, encontrou resistência, tendo sido criticado tanto por se tornar uma forma de deslegitimar opiniões e discursos simplesmente pela forma com que se apresentavam, quanto por criar textos de difícil apreensão e, portanto, elitistas. As críticas à posição antirrealista também apontaram "as limitações de uma crítica

9 No campo da ficção, Laura Mulvey, autora do ensaio seminal da teoria feminista de cinema Prazer visual e cinema narrativo, publicado originalmente em 1975 (traduzido e publicado no Brasil em 1983 no livro A Experiência do Cinema, organizado por Ismail Xavier), afirma que a chave para a criação de um contra-cinema feminista radical era a negação dos códigos desenvolvidos pelo cinema dominante: "Um cinema de vanguarda estética e política é agora possível, mas ele só pode existir enquanto contraponto" (Mulvey, 1983, p. 439).

10 Dora Kaplan relatou a excitação gerada por alguns dos filmes de não-ficção e o painel "Making Documentaries" no Primeiro Festival Internacional de Filmes de Mulheres em Nova Iorque. Nas suas discussões sobre como os acontecimentos dos anos 1960 facilitaram o florescimento dos documentários feministas, Kaplan comentou a invenção de equipamento leve associado ao cinema verité, descrito como "o documentário que permitiu que a realidade acontecesse na tela" (Waldman; Walker, 1999, p.6-7, tradução nossa).

Dossiê Feminismos vitais - https://revistaecopos.eco.ufri.br/

ISSN 2175-8689 - v. 24, n. 1, 2021

DOI: 10.29146/ecopos.v24i1.27603 
demasiado ampla que não permite distinções entre o uso dessas estratégias para diferentes fins políticos" (Waldman; Walker, 1999, p. 12, tradução nossa).

E. Ann Kaplan (1988), ao olhar para esse embate com o distanciamento de quase uma década, propõe uma mudança de enfoque: afinal, se o que interessava era a possibilidade de os filmes interferirem e melhorarem a vida cotidiana das mulheres, a análise sobre eles deveria ser feita a partir de seu potencial de transformação social. Assim, ao revisar as teorias que criticam o realismo no documentário feminista, e a partir da análise de dois filmes do período ${ }^{11}$, ela conclui que as mesmas técnicas cinematográficas podem ser usadas para expressar valores bastante distintos. Com essa conclusão, ela busca reposicionar a querela sobre o realismo, retirando-a do centro do debate:

Quando se faz uma observação detalhada de filmes realistas, compreende-se a falibilidade das grandes generalizações. Ou seja, os filmes realistas são muito mais heterogêneos e complexos em suas estratégias do que admite a crítica teórica. Precisamos de uma teoria que permita e aceite posicionamentos diversos ante questões econômicas e de classe no método realista (Kaplan, 1995, p. 186).

Para a autora, as questões ideológicas são mais importantes na elaboração de estratégias de mudança, e, se há problemas nas técnicas realistas, eles não estão diretamente ligados às técnicas em si, mas ao discurso que sustenta as suas narrativas. Desse modo, reconhecendo seus limites e compreendendo-as não como verdade, mas como um sistema de representação, as técnicas poderiam ser encaradas de maneira menos dogmática e continuar disponíveis como possibilidades discursivas para as cineastas feministas.

Esse fervoroso debate dividiu realizadoras e teóricas do cinema feminista, gerando uma série de textos e filmes que experimentavam e testavam as suas posições. Entretanto, posteriormente - como observou Teresa de Lauretis (1994) a partir de uma análise minuciosa do lugar da espectadora feminina e da forma como esses filmes se dirigiam a ela -, tais tendências, menos do que rivais, podem ser vistas como complementares:

Se repensarmos o problema de uma especificidade do cinema das mulheres e das formas estéticas em termos de endereçamento - quem está fazendo filmes para quem, quem está olhando e falando, como, onde e para quem - então o que tem sido visto como uma

11 "Joyce at 34" (de Joyce Chopra, 1972) e "Janie's Janie" (de Newsreel, Geri Ashur, Peter Barton, Marilyn Mulford \& Stephanie Palewski, 1971).

Dossiê Feminismos vitais - https://revistaecopos.eco.ufri.br/

ISSN 2175-8689 - v. 24, n. 1, 2021

DOI: 10.29146/ecopos.v24i1.27603 
divisão, um racha ideológico dentro da cultura feminista do cinema entre teoria e prática, ou entre formalismo e ativismo, pode parecer a própria força, o impulso e a heterogeneidade produtiva do feminismo (Lauretis, 1994, p. 35).

\section{Estratégias estético-políticas na obra de Weinstein}

Na década de 1960, haviam entrado no mercado estadunidense as câmeras de cinema leves e o equipamento de som direto, que criaram possibilidades estéticas fundamentais para o desenvolvimento do documentário autobiográfico. Poder filmar com equipes mínimas, ou até mesmo individualmente, viabilizou a entrada no universo doméstico com filmagens mais intimistas.

Weinstein fazia parte de um grupo que trabalhava a autoinscrição a partir da tradição do cinema direto, que, como demonstra Tonelo (2017), apesar de ter partido de uma matriz realista, promovia um processo continuado de revisão de suas bases teóricas e de reinvenção de suas estratégias estéticas. Assim, Weinstein produzia e experimentava em meio a um ambiente onde a efervescência da produção cinematográfica acontecia em estreito diálogo com o desenvolvimento teórico:

Ainda na década de 1970 e na década de 1980, o debate acerca do desenvolvimento do
cinema direto estava em ascensão. Cineastas como Ed Pincus e seus pupilos estudavam
possibilidades criativas de lidar com a cotidianidade (everydayness) e com a
representação do "Eu" do cineasta e de seu universo doméstico em um movimento que
apenas começou na metade da década de 1970 e consolidou-se na década de 1980.
Existia uma ebulição teórica acontecendo em centros universitários como o MIT Film
Section, que apontava para novos caminhos do cinema direto. Um dos princípios destes
caminhos consistia na consideração de aspectos de autorreflexão do cineasta, de seu
universo doméstico e de seus laços familiares - uma narrativa decididamente
autobiográfica - que partia de desenvolvimentos tecnológicos e metodológicos que ainda
estavam sendo estudados (Tonelo, 2017, p. 79).

Além disso, havia uma interlocução com movimentos feministas em atividade na época. Weinstein convivia com Jane Pincus, uma das fundadoras do coletivo Boston Women's Health Book Collective, que, a partir de um workshop sobre o corpo das mulheres, em 1969, elaborou o livro Our Bodies, Ourselves. 0 livro propõe compartilhar conhecimentos sobre o corpo de forma acessível, para que as mulheres sejam capazes de aprender "sobre si próprias, para que possam 
comunicar as suas descobertas aos médicos e possam desafiar o estabelecimento médico a mudar e a melhorar os cuidados que recebem"12. Teve a sua primeira tiragem comercial em 1973, e foi reeditado diversas vezes nas décadas seguintes, além de traduzido para trinta e três línguas. Já o coletivo funcionou até 2018 como uma organização sem fins lucrativos em prol da saúde da mulher. A emergência e a enorme relevância de Our Bodies, Ourselves e do trabalho do coletivo são fruto da efervescência na luta feminista da época.

Foi nesse contexto que as questões feministas começaram a ser abordadas por algumas diretoras, cujos trabalhos passam também pelo documentário autobiográfico. Podemos citar a obra da diretora Joyce Chopra, que realiza diversos documentários com temas sociais e relacionados às questões das mulheres, entre eles "Joyce at 34" (1974) ${ }^{13}$, um documentário autobiográfico em que aborda o nascimento e os primeiros anos de sua filha, bem como as formas que encontra para manter sua vida profissional ativa. Ou a obra de Amalie Rothschild, fotógrafa e cineasta que dirigiu, entre outros, o documentário autobiográfico Nana, mom and $m e(1974)^{14}$, no qual examina as relações entre ela própria, a sua mãe artista e a sua avó - em 2007 o filme foi premiado pelo seu papel pioneiro no cinema autobiográfico no Festival Biografilm em Bolonha, Itália. Ou, ainda, podemos citar o trabalho de Maxi Cohen, que no filme Joe and Maxi (1978) ${ }^{15}$, dirigido em parceria com Joel Gold, aborda a conflituosa relação com o pai depois da morte de sua mãe aos 44 anos, de câncer. Ou a criação de Susana Blaunstein ${ }^{16}$, cineasta argentina que, vivendo nos EUA, realizou o curta Susana (1980), uma autobiografia documental que opta por expor os conflitos familiares e internos criados a partir do desejo da diretora por outras mulheres.

Na obra de Weinstein - e nas de muitas de suas colegas -, a apropriação das novidades tecnológicas se deu de forma a questionar os papéis sociais reservados para homens e mulheres e a subverter as relações de poder estabelecidas entre eles. A autoafirmação no papel de direção, posição dominada pelos homens, une a todas: nesse ambiente hostil, tomar para si

\footnotetext{
12 https://www.ourbodiesourselves.org/our-story, Acesso em 29 jan. 2021. Tradução nossa.

13 Disponibilizado pela própria diretora em seu perfil no site Vimeo: https://vimeo.com/431091892. Acesso em 29 jan. 2021.

14 Mais informações em http://www.amalierrothschild.com/filmography.html Acesso em 29 jan. 2021.

15 A diretora disponibilizou um trecho do filme em http://www.maxicohenstudio.com/films/joe-and-maxi/. Acesso em 29 jan. 2021.

16 Cineasta argentina formada em Artes no Instituto de Artes de São Francisco.
} 
os meios de produção documental, determinando quem será filmado, como e onde, escolhendo as perguntas a serem feitas, as estratégias estéticas a serem adotadas e definindo a estrutura narrativa na montagem, era por si só um ato transgressor.

No caso de Weinstein, algumas estratégias podem ser destacadas. Ao empunhar a câmera e apontá-la para os homens, ela inverte as posições hierárquicas estabelecidas. Se, historicamente, os homens dominavam o papel de sujeitos do discurso e as mulheres eram, via de regra, objetos dos discursos - como demostraram as análises de Mulvey e de Johnston, por exemplo -, Weinstein não só se apropria do lugar discursivo (sendo aquela que fala), como, ao tematizar os homens de sua família, torna-os objetos de suas narrativas (aqueles sobre quem se fala). Ao mesmo tempo, opera uma disputa dentro da instituição familiar, o que fica evidente em seu primeiro filme, quando, ao indagar e expor a visão do pai em uma narrativa construída e dominada por ela - portanto, incorporando as declarações dele em sua própria argumentação -, destitui a autoridade da fala paterna como o único discurso legítimo.

As maneiras pelas quais aborda o companheiro Peter também revelam estratégias de deslocamento de posições, que aparecem nas linhas e nas entrelinhas dos filmes. Ao debater a questão do casamento, e ao expor os conflitos do casal em seu segundo filme, Weinstein não apenas consegue colocar o seu ponto de vista e a si mesma de maneira contundente, como persegue seu objetivo - casar-se - e, ao final, o alcança. Assim, ainda que seja Peter a presenteála com o anel de noivado, é ela que, ao fazer o filme, protagoniza a ação. No seu último filme, Weinstein faz uma crítica verbal sobre a insuficiência de Peter como pai e companheiro, ao mesmo tempo em que constrói sua narrativa sobre a maternidade com a ausência total do marido. Nesse filme, que encerra o seu ciclo de curtas autobiográficos, as figuras masculinas, tão centrais anteriormente, desaparecem.

Weinstein, ao explorar a sua própria presença nos filmes, coloca-se como uma diretoraperformer ${ }^{17}$. Sua voz por detrás da câmera - dando a ver o extracampo -, suas incursões para dentro do quadro nos monólogos do segundo filme, ou sua presença constante na frente na

17 Stella Bruzzi, no livro New Documentary, debruçou-se longamente sobre as relações entre documentário e performance: "O que reiteram os documentários baseados em diretores-performers são as noções simultâneas de que um documentário é seu próprio documento e que o documentarista intervencionista é uma entidade fluida, definida e redefinida em cada contexto em que aparece" (Bruzzi, 2006, p. 198, tradução nossa). A autora vê o documentário como fruto de relações dialéticas e de contradições entre elementos narrativos e estruturais, e ao trazer para o corpo do filme a consciência de que ele é uma escritura, estabelece com o espectador um pacto mais honesto.

Dossiê Feminismos vitais - https://revistaecopos.eco.ufri.br/

ISSN 2175-8689-v. 24, n. 1, 2021

DOI: $10.29146 /$ ecopos.v24i1.27603 
câmera no terceiro e no quarto filmes, ligam o campo com o fora-de-campo e revelam o processo de construção da narrativa. Ademais, o conjunto de filmes, ao abordar diferentes momentos da vida da diretora, bem como as transformações pelas quais ela passa durante quase uma década, dão a ver o processo de construção e de reconstrução da própria “diretorapersonagem-performer", que não se estabelece como uma identidade fixa, mas que se apresenta como um ser em constante mutação.

Outro aspecto relevante é a forma como Weinstein se relaciona, por meio dessas estratégias performativas, com a espectadora de seus filmes. A relação das cineastas com as espectadoras é um tema importante do pensamento feminista. Segundo Lauretis, "a subjetividade de gênero não está apenas implicada no encontro do espectador com cada filme, mas, também, construída, reafirmada ou desafiada, deslocada ou transferida" (Lauretis, 1989, p. 96, tradução nossa). Assim, para a autora, a capacidade de incidência do cinema no mundo real, ou seja, sua possibilidade política, reside no seu inerente processo de produção de subjetividade nos espectadores, e sublinhar que a subjetividade a ser produzida é sempre relacionada ao gênero é o que permite uma perspectiva feminista na produção e na crítica cinematográficas.

Uma razão, e não a menor, pela qual o espectador é fundamental para o que chamei de cinema feminista é que a sua preocupação com a endereçamento (a quem o filme se dirige, a quem fala, o que e para quem procura representar, quem representa) se traduz num esforço consciente para se dirigir ao público como mulher, independentemente do sexo dos espectadores; e é isso que permite que o filme traga para a sua textura discursiva algo daquele "real" que é a experiência não-teorizada das mulheres (Lauretis, 1989, p. 118, tradução nossa).

Mostrar as entranhas da produção para a espectadora é uma forma de implicá-la na construção do próprio filme; dirigir-se diretamente a ela, por meio de monólogos para a câmera ou pelo uso de voz em off, é outra. Weinstein lança mão de ambas.

No livro A aventura de contar-se: feminismos, escrita de si e invenções da subjetividade, Margareth Rago (2013) destaca a importância da construção da subjetividade na emancipação feminina. Para a autora, o ato de contar a própria história é fundamental nesse processo, pois não só constitui uma apropriação da própria narrativa, como, no compartilhamento, proporciona a identificação e o diálogo com outras mulheres. Assim, as escritas de si feministas

Dossiê Feminismos vitais - https://revistaecopos.eco.ufrj.br/

ISSN $2175-8689$ - v. 24, n. 1, 2021

DOI: 10.29146/ecopos.v24i1.27603 
"enfatizam e se comprometem com as lutas contra as formas contemporâneas de controle biopolítico dos corpos e com as buscas de formação de novos modos de expressão subjetiva, política e social" (Rago, 2013, p. 56). Nos documentários autobiográficos de mulheres, a construção de novas possibilidades de existência a partir das histórias pessoais muitas vezes passa por uma revisão das relações familiares, abordando traumas e mágoas, expectativas e frustrações.

A obra de Weinstein faz parte de um momento no qual o campo do documentário explorava novas estratégias, entre elas as performativas, enquanto o feminismo criava formas de organização e ação. Essa crescente atividade - tanto no campo político e militante quanto no campo teórico - foi determinante para as práticas cinematográficas de cineastas mulheres que, de alguma forma, se envolveram com as demandas e as reflexões feministas.

\section{Considerações finais}

Como parte de um grupo que investigava o documentário autobiográfico a partir das bases do cinema direto e que, quer do ponto de vista da realização de filmes, quer da elaboração teórica, experimentava formas de ampliar os limites de sua própria tradição, os filmes de Weinstein se situam em um momento de efervescência do documentário na região de Boston.

A noção de observação "mosca-na-parede" e a subtração narrativa de elementos que revelassem a presença dos cineastas na tomada dão lugar à participação e à ênfase da interação do realizador com as pessoas filmadas no momento da tomada. Buscava-se tematizar a experiência estadunidense naquele momento específico a partir da vida individual do cineasta, de seu cotidiano e daquilo que sua interação com as pessoas mais próximas de si poderia oferecer, frequentemente em uma esfera familiar (Tonelo, 2017, p. 133-134).

Dessa forma, percebe-se que as preocupações em torno do realismo se davam não só no campo do feminismo. No contexto do grupo de Cambridge (e em outros campos de estudos do documentário) era também um tema gerador de questionamentos, proposições e experimentações. 
MacDonald (2013), ao refletir sobre a obra dos cineastas de Cambridge, conclui que os filmes adquiriram, ao longo do tempo, sentidos que ultrapassam a intenção com que foram concebidos ou o efeito que tiveram à época de seu lançamento. 0 autor afirma que, com o passar dos anos, esses filmes tornaram-se, também, documentos de uma época:

O que começou como uma variedade de tentativas de descrever e de analisar os sentimentos e atividades mais pessoais dos cineastas, tornou-se cada vez mais a evidência etnográfica sobre a vida nos Estados Unidos, incluindo a mudança do papel da realização de filmes na vida familiar. (MacDonald, 2013, p. 134, tradução nossa).

Consequentemente, os filmes de Miriam Weinstein podem ser vistos como documentos, ou evidências, não só de uma forma de viver, mas de um tipo de questionamento feminista que marcou uma época e de um fértil momento de investigação artística no campo do documentário. Ao lidar com temas e relações estruturalmente coercitivos para uma mulher, ela avançou, recuou, negociou e respondeu com os seus filmes. As contribuições estético-políticas de sua obra, com efeito, são parte do legado de toda uma geração de cineastas mulheres feministas.

\section{Referências bibliográficas}

BRUZZI, Stella. New Documentary. Oxon: Routledge, 2006.

JOHNSTON, Claire. Women's Cinema as a Counter Cinema. In: JOHNSTON, Claire. (ed.). Notes on Women's Cinema. London: Society for Education in Film and Television, 1973.

JUHASZ, Alexandra. Bad Girls come and go, but a lying girl never be fenced in. In: WALDMAN, Diane; WALKER, Janet (orgs). Feminism and Documentary. London: University of Minnesota Press, 1999.

KAPLAN, Elizabeth Ann. A mulher e o cinema: os dois lados da câmera. Rio de Janeiro, RJ: Rocco, 1995. Theories of the Feminist Documentary. In: Rosenthal, Alan. (org). New Challenges for Documentary. Berkeley: University of California Press, 1988.

LAURETIS, Teresa de. A tecnologia de gênero. In: HOLANDA, Heloísa Buarque de. Tendências e impasses: o feminismo como crítica cultural. Rio de Janeiro, RJ: Rocco, 1994. . Technologies of Gender: essays on theory, film and fiction. London: Macmillan, 1989.

MACDONALD, Scott. American ethnographic film and personal documentary: the Cambridge turn. 
Berkeley: University of California Press, 2013.

MULVEY, Laura. Prazer Visual e Cinema Narrativo. In: XAVIER, Ismail. (org.). A Experiência do Cinema. Rio de Janeiro, RJ: Edições Graal: Embrafilme, 1983, p. 437-454.

RAGO, Margareth. A aventura de contar-se: feminismos, escrita de si e invenções de subjetividade. Campinas, SP: Editora da Unicamp, 2013.

TONELO, Gabriel. A Escola de Cambridge e o desenvolvimento do documentário autobiográfico norteamericano. Rebeca: Revista Brasileira de Estudos de Cinema e Audiovisual, ano 3, v. 6, p. 28-52, jul./dez., 2014.

O documentário autobiográfico: o cinema de Cambridge e a obra de Ross McElwee. Tese de doutorado. Campinas, SP: [s.n.], 2017.

WALDMAN, Diane; WALKER, Janet. (orgs.). Feminism and Documentary. London: University of Minnesota Press, 1999. 